Jaka Repič

\title{
Gibanje kot prostorske prakse in ekonomske strategije na primeru družinskega sirarstva $v$ Bohinju
}

Ključne besede: Bohinj, gibanje, poti, krajina, sirarstvo, družinske kmetije DOI: 10.4312 /ars.8.1.38-57

\section{Uvod}

Sodobno mlekarstvo in sirarstvo v Bohinju temeljita na uveljavljanju, reprezentaciji in prodaji lokalnih izdelkov, ki poleg mleka in mlečnih izdelkov, predvsem sira, obsegajo tudi produkcijo lokalnosti in trženje dediščine, zlasti $\mathrm{v}$ turističnem in kulinaričnem kontekstu. Slednje je s sirarstvom povezano skozi reprezentacije kulturne krajine, dediščino planšarstva ter biološkega oziroma ekološkega kmetijstva. Tako je na primer na siru Bohinjske sirarne upodobljen lik planšarja, opis pa pravi, da je njihov sir izdelan iz "zdravega bohinjskega mleka, ki je pridobljeno v čistem naravnem okolju« in na način, ki »združuje tradicijo, znanje, večstoletne izkušnje sirarjenja in sodobno opremo« (Bohinjska sirarna, www.sir.si). Sir in druge mlečne izdelke poleg Bohinjske sirarne proizvaja še nekaj manjših, družinskih sirarskih kmetij v Spodnji in Zgornji Bohinjski dolini, nekatere od njih pa tudi na planinah. Bohinjski sirarji aktivno soustvarjajo lokalno krajino $\mathrm{v}$ reprezentativnem smislu (vključevanje v turistični imaginarij in infrastrukturo), fizično agronomskem smislu (paša, planšarstvo in skrb za kmetijske površine, planine in poti) ter v kulturnem smislu (podobe, vezane na planšarstvo, Alpe in domačo proizvodnjo). S tem sirarji sooblikujejo tudi koncepte avtentičnosti, pristnosti in lokalnosti, saj se opirajo na tradicionalne družbeno-ekonomske modele (zlasti zadružniške oblike pastirske in sirarske dejavnosti, skupna uporaba planin) ter na krajinsko, tehnološko in kulturno dediščino.

O planšarstvu in sirarstvu v Bohinju je pisalo že veliko avtorjev (na primer Cevc, 1992; Novak, 1989; 1995; Ledinek Lozej, 2002; 2013), ki so opisali tudi zadružni model kmetijstva, a so redko posebej izpostavili vidik poti, gibanja in mobilnosti kot temeljne prostorske prakse v zadružni in družinski sirarski ekonomiji. Ta prispevek se torej posebej osredotoča zlasti na vidik gibanja, poti in krajev, ki jih vzpostavljajo in opredeljujejo prakse v sirarski ekonomiji, ter na implikacije za (pre)oblikovanje, 
dojemanje, prisvajanje in trženje okolja in krajine. $\mathrm{V}$ prvem delu članka na kratko predstavim zgodovino sirarstva v Bohinju, ki se je bolj ali manj opirala na planšarstvo, torej pašo ter pridelavo mleka in mlečnih izdelkov na bohinjskih planinah, obenem pa je variirala med družinskim in zadružnim kmetijstvom. V drugem delu članka pa predstavim primer ekonomskih praks in strategij družinske sirarske kmetije skozi pletež poti, stez, cest in krajev, po katerih ali med katerimi se člani družinske kmetije gibljejo in s tem soustvarjajo kulturno, turistično in ekonomsko krajino v Bohinju. Pri tem povezujem različne ravni rednih in občasnih praks gibanja, med njimi dnevno pašo pri vaseh, pastirstvo, pot na planine in planinsko pašo, urejanje poti, vključevanje v turistično sirarsko pot, pa tudi poti na tržnice, sejme in v druge kraje, kjer prodajajo sire, maslo, skuto, jogurt in druge mlečne izdelke. Gibanje je temeljna praksa navidezno dokaj statične - kmečke - dejavnosti, ki oblikuje tudi ekonomske strategije zadružnega in družinskega kmetovanja ter konceptualizacijo, organizacijo in reprezentacijo prostora - vasi z okolico, poti, planine in drugega pašnega okolja ter turističnega in kulinaričnega prostora.

\section{Kratka zgodovina sirarstva $\vee$ Bohinju in povezava $s$ praksami mobilnosti}

\section{Zadružno sirarstvo}

Sirarstvo $\mathrm{v}$ Bohinju je močno povezano $\mathrm{z}$ mobilnostjo, zlasti planšarstvom in trgovanjem, ter variacijami med družinskim in zadružnim modelom kmetijstva. Ekonomsko je bohinjska regija dolgo temeljila predvsem na železarstvu in z njim povezanem rudarstvu, gozdarstvu in lesarstvu ter na kmetijstvu, kjer je najpomembnejša živinoreja s pridelavo mleka in mlečnih izdelkov. Tudi vaška družbena organizacija je bila močno naslonjena na kmetijstvo. Vasi so se organizirale v t. i. srenje (pašne upravičenke oziroma predhodnice agrarnih skupnosti), ki naj bi nastale že $\mathrm{v}$ predfevdalnem obdobju kot upravičenke za pašo na planinah in $\mathrm{v}$ gozdovih. Tudi $\mathrm{v}$ fevdalizmu so fevdalni gospodi srenjam dajali planine $\mathrm{v}$ zakup oziroma proti plačilu $\mathrm{v}$ siru in mlečnih izdelkih, občasno pa so jih dali tudi tujim pastirjem, kar je ponavadi pripeljalo do konfliktov (Novak, 1995, 28). Bohinjske planine so namreč srenje - ne glede na pravno lastništvo - imele za lastno in skupno (interesno) okolje. Srenje so ostale pašne upravičenke tudi po zemljiški odvezi leta 1848, članstvo v srenji pa je bilo povezano s priposestvovanjem ali vplačilom v srenjo (Ledinek Lozej, 2002, 74; Novak, 1995). Do poznega 19. stoletja je pastirstvo s proizvodnjo mleka in mlečnih izdelkov temeljilo na družinskem kmetijstvu in članstvu v srenjah. Izdelke, zlasti sir in kuhano maslo, pa so kmetje najpogosteje prodajali v Trstu. 
V sedemdesetih letih 19. stoletja so v Bohinju z ustanavljanjem sirarskih društev uvedli zadružni model sirarstva, v katerem so se srenje - kasneje agrarne skupnosti okrepile in dalje ohranjale pravice do paše na planinah. Po letu 1870 so namreč povsod na Kranjskem sirarstvo reorganizirali s pomočjo ustanavljanja mlekarskih in sirarskih društev, kar je povzročilo hiter razvoj planšarstva in sirarstva kot temeljnih ekonomskih strategij v bohinjskem kmetijstvu. Pred tem je bila pridelava mleka, sira in mlečnih izdelkov dejavnost posameznih kmetij, z zadružnim modelom ter pridelavo in prodajo kvalitetnega sira pa je tudi sirarstvo močno napredovalo. Predvsem je bila pomembna pobuda župnika iz Bohinjske Bistrice Janeza Krstnika Mesarja, ki je bil od leta 1871 načelnik bohinjske podružnice Kmetijske družbe in je leta 1873 ustanovil prvo sirarsko družbo za Bohinjsko Bistrico, Bitnje in Lepence. Poleg tega je pripeljal švicarskega sirarja Tomasa Hitza, ki je sicer učil lokalne sirarje na Tolminskem, na planini Razor in v Polubinu, da je sirarstva izučil tudi bohinjske sirarje. Hitz je tako opisal navdušenje nad uspehom začetka zadružnega sirarstva $\mathrm{v}$ Bohinju, ki je prineslo visoke dobičke $s$ prodajo trgovcem v Ljubljani:

Ta srečni vspeh je med ljudstvom toliko veselja vzbudil, da so se že v prihodnjem letu (1874) ustanovile tri nove družbe v okolici BistriškiBohinjski: v Nemških Rovtah, v Nomnu in Ravni (Hitz, 1876, 269).

Zadružna organizacija je nadaljevala tradicionalne oblike srenjskega pašništva in urejanja planinskega okolja. Prakse sodelovanja in medsebojnih obligacijskih razmerij (pašne pravice, članstvo, delo na planinah in poteh) so razvili pod gorskimi okoljskimi pogoji, v okviru možnosti urejanja medsebojnih ekonomskih razmerij, pomoči in solidarnosti ter upoštevajoč načelo dobrega gospodarjenja. Solidarnosti niso organske, ampak ekonomske prakse, ki so omogočale lažje kmetovanje ter preživljanje v gorskem in podalpskem okolju (primerjaj podobno ugotovitev za dolino Trente pri Simoniču, 2014). Pri takšni organizaciji medsebojnih razmerij so imeli pomembno vlogo nekateri ključni akterji v vaških skupnostih, sirarskih društvih in kasneje $\mathrm{v}$ agrarnih skupnostih. Hitz je na primer poudaril, da so uspehom botrovale zasluge župnika Mesarja, predvsem pa njegovo poučevanje »švicarskega načina« pridelave sira; ta prinaša visokokakovosten proizvod, ki ga je lažje prodati:

Na planini Ravni je izdeloval sir neki Bohinjec, izobražen mladenič, in sicer ne po stari navadi, ampak na način, kakor se ga je navadil pri nas v Polubinu in na planini Razor ... Čisto, urno delo, raba termometra in drugih orodij, kakor tudi visoka cena, za katero se je prodal Ravnikov sir, storilo je jako dober vtis na druga društva. ... [Ž] e štiri društva [so se] odločila, da bodo letos izdelovala sir na Švicarski način (Hitz, 1876, 269).

Hitz je pri ustanavljanju sirarskih društev pomagal z izobraževanjem sirarjev, pa tudi z nasveti glede opremljanja sirarn in uporabe orodij. Sirarne so opremili 
po njegovih navodilih in $\mathrm{z}$ orodji, ki so jih pripeljali iz Kobarida ali celo iz Švice. Tudi kasneje so se nekateri bohinjski sirarji izobraževali v Švici. Razvoj sirarstva je tehnološko temeljil na »švicarskem načinu« sirjenja (uporablja se metoda ementalca), družbeno pa na organizaciji sirarskih društev, ki so delovala kot zadružne skupnosti. Združevanje kmetov $\mathrm{v}$ sirarskih društvih je spremenilo nekatere ekonomske in prostorske prakse: povečala se je vzreja goveda, zmanjšala pa se je vzreja drobnice, ki je bila pomembna pri preprečevanju zaraščanja planin. Predvsem se je spremenila oblika organizacije dela v skupnem gorskem okolju. Postavili so skupne sirarne na planinah, še bolj pa se je utrdila že obstoječa transhumanca oziroma večmesečna selitev živine in pastirjev (majerjev) na planine na različnih višinah. ${ }^{1}$

Pridelava mleka, mlečnih izdelkov in predvsem sira ni bila dejavnost, omejena le na dolino, ampak se je razvila tudi na bohinjskih planinah, kjer so z zadružnim modelom uvedli sirjenje v skupnih sirarnah in organizirano v okviru agrarnih skupnosti. Pasli so na planinah na različnih višinah - spomladi na vaških pašnikih in najnižjih senožetnih planinah (rotih), pozno spomladi in jeseni na srednje ležečih, poleti pa na najvišjih planinah (glej Cevc, 1992, 44-45). Novonastala društva so bila sprva finančno šibka, za izgradnjo skupnih sirarn in druge izdatke so si pogosto izposodila denar, ki so ga po prodaji sira vrnila, drug prihodek pa razdelila članom zadruge glede na število krav in njihov donos:

Skupaj spravljeno mleko so dvakrat ob času sirarstva na planini Bitinjski in enkrat na Govnjaču vagali; po razmeri tega vaganja so izračunili, koliko pride mleka na enega združnika in pa koliko dobička iz prodanega sira (Belrupt, 1875).

Organizacija sirarstva, nakup opreme in drugi stroški so torej temeljili na ekonomski vzajemnosti in zadružni participaciji članov agrarne skupnosti. Takšna organizacija je pomenila vzajemno obliko dela in uporabe naravnih virov, pa tudi obliko recipročnosti v družbenih odnosih. Za urejanje skupnih objektov na planinah (predvsem za sirarno) so zbrali sredstva pašni upravičenci, prav tako so participirali pri urejanju planin, okolice in poti. Pašna pravica je bila vezana na kmetijo $-\mathrm{z}$ dedovanjem kmetije se deduje tudi pravica do paše na planinah in pašnikih agrarne skupnosti. Uvoz in poučevanje sirarske tehnologije, intenzivna propaganda in zadružna organizacija so močno vplivali predvsem na razvoj planšarstva in skupnega sirjenja ter prodaje sira:

$S$ posebnim veseljem moremo povdarjati to, da so Bohinjci koj pravo pot $\mathrm{v}$ svojem podvzetji nastopili, to je, da so skupno prodajanje sira vpeljali (Belrupt, 1875).

1 V slovenski literaturi je v uporabi tudi izraz večstopenjska paša (na primer Ledinek Lozej, 2013).

Transhumanco pa uporabljam, ker gre poleg paše tudi za selitev in bivanje v planinskem okolju. 
Valenčič (1990) navaja, da sirarske družbe, ki so bile formalna oblika predhodne srenjske družbeno-lokalne organizacije, sicer sprva niso temeljile na "avstrijskem zakonu o pridobitnih in gospodarskih zadrugah z dne 9. aprila 1873«, saj so se družbe uradno spremenile v zadruge šele več desetletij kasneje. »Prva se je preosnovala $\mathrm{v}$ zadrugo med bohinjskimi sirarnami sirarska družba v Stari Fužini, ki se je vpisala v zadružni register leta 1910« (Valenčič, 1990, 39). Ne glede na to pa so sirarske družbe v Bohinju ves čas delovale kot zadruge, torej s skupno gospodarsko dejavnostjo in združevanjem paše, sirjenja, organizacije dejavnosti, dela in prostorov. Cevc (1992) navaja devet srenj oziroma agrarnih skupnosti v bohinjski regiji: Studorska oziroma studorsko-fužinarska (vasi Studor in Stara Fužina), Srenjska (Srednja vas), Češnjiška, Bukovska, Bitenjska, Rotarska, Ravenska, Bistriška in Nomenjska. Studorskofužinarska agrarna skupnost je obsegala nizko ležeče pašnike ob jezeru, senožetne planine Voje, Blatca, Ukanc, Vogar in Rudnica, spodnje planine Blato, Hebed, Vodični vrh, Grintojca, Vratača in Trsje ter visoke planine Pri jezeru, Dedno polje, Viševnik, Ovčarija, Laz in Tosc.

$\mathrm{V}$ času Kraljevine Jugoslavije so bile srenje preimenovane $\mathrm{v}$ agrarne skupnosti. Leta 1947 so bile ukinjene, pristojnosti upravljanja s planinami in planšarstvom pa so bile prek občin prenesene na kmetijske zadruge (Vojvoda, 1995, 18-19). V Bohinju so razvijali predvsem gozdarstvo, planšarstvo pa so opuščali tudi zaradi razvoja hlevne živinoreje in splošne deagrarizacije prebivalstva. Problem ohranjanja kmetij se je pokazal zlasti pri slabem prenosu kmečke dejavnosti na mlajše prevzemnike. Vojvoda navaja, da je bilo v Zgornji bohinjski dolini leta 1931 kmečkega prebivalstva 82,4 \%, do leta 1961 je njegov delež upadel na 47,7 \%, leta 1991 pa zgolj na 12,1\%. $\mathrm{V}$ času socialistične Jugoslavije je planšarstvo izgubljalo na pomenu, nadomeščali so ga hlevna živinoreja, odkup mleka ter pridelava sira v sodobni sirarni, ki so jo leta 1971 postavili v Srednji vasi. »Novi sirarski obrat v dolini je naznanil konec zadružno organiziranega sirarstva na planinah, ki se je začelo leta 1873 (Novak, 1989, 123). Kmečka zadruga je na planine nehala pošiljati pastirje, posamezni pašni upravičenci pa so ohranjali prakse planšarstva in sirjenja, bodisi samostojno ali neformalno $\mathrm{v}$ okviru prejšnjih sirarskih zadrug. $Z$ namenom vsaj minimalnega ohranjanja pašništva $\mathrm{v}$ planinah je bila $\mathrm{v}$ sedemdesetih letih 20. stoletja pašna pravica razširjena na pašne interesente, leta 1993 pa so bile v okviru denacionalizacije ponovno vzpostavljene agrarne skupnosti in pašne pravice njihovih članov (Ledinek Lozej, 2002, 75). Kljub temu, da se je število pašne živine po drugi svetovni vojni zmanjšalo, transhumanca ni zamrla, vsaj ne povsod. Na precej planinah se je pašno kmetijstvo ohranilo, a se razen obujanja pašništva na posameznih planinah (na primer na Voglu) število živine in pašne površine na splošno zmanjšuje (za bohinjske planine in posebej za planino $\mathrm{v}$ Lazu glej Jeraj, 2012, 6-8). 
$\mathrm{V}$ zadnjem desetletju se je tudi sirarska dejavnost v Bohinju zaradi vse težjih gospodarskih razmer $\mathrm{v}$ regiji in razvoja turistične infrastrukture precej spremenila. $\mathrm{S}$ sirarstvom se je poleg Bohinjske sirarne začelo (ponovno) ukvarjati več manjših družinskih kmetij, ki so se po eni strani naslonile na tradicionalne oblike sirarstva, obenem pa so oblikovale tudi nove ekonomske in prostorske prakse. Zgornji opis zgodovine sirarstva prikazuje uporabo različnih ekonomskih strategij, vezanih na zadružni in zasebni model kmetijstva, ki so se v lokalni skupnosti uveljavljale glede na okoljske vire, tehnologije in nacionalni kontekst razvoja kmetijstva. V nadaljevanju se članek osredotoči na vprašanje poti in kulturne krajine, ki jo oblikujejo različni akterji - pastirji, agrarne skupnosti, planinci, turistična društva itd. Poti in krajina so odraz ekonomskega in družbenega razvoja kmetijstva in sodobnih sprememb v ekonomiji, zlasti s poudarkom na turizmu. Videli bomo, kako so se značilnosti planin in gorskega okolja spremenile z vikendaštvom, turizmom in planinsko dejavnostjo. Obenem pa tudi pastirji ostajajo med ključnimi akterji, ki krajino v Bohinju sooblikujejo z različnimi oblikami gibanja skozi dolinsko, pašno in gorsko okolje.

\section{Planšarstvo, poti, kulturna krajina}

Na višinskih pašnikih in planinah v Bohinju poznajo transhumantno obliko paše. Pozimi so živino krmili v hlevu, od pomladi do jeseni pa so jo gnali na pašo - najprej na nizko ležeče pašnike blizu vasi, kasneje na višje. Na visokih planinah so pastirji čez poletje ostali z živino, sirarji pa proizvajali sir v skupni sirarni. V bližini vasi so spomladi izkoriščali srenjske pašnike (zdaj uporabljajo lastne ali najete pašnike), nato senožete in nizke planine, v visokem poletju pa najvišje ležeče planine, kjer so ostali približno dva meseca. Ob koncu poletja so živino gnali proti dolini v obrnjenem vrstnem redu. Senožeti so bili pomembni predvsem za košnjo in spravilo sena za zimske mesece, niso pa tam dlje bivali (glej Cevc, 1992, 62-87). Zato so bili objekti na nižjih planinah namenjeni predvsem za orodje, seno in zatočišče, na višjih planinah pa za pastirske stanove. $\mathrm{V}$ nižjih in višjih planinah pa so pastirji (majerji) ostajali od konca junija do prvih dni septembra.

Predfevdalna in fevdalna srenjska organizacija planšarstva, še bolj pa zadružna organizacija mlekarstva in sirarstva sta bili z izkoriščanjem planin in drugih pašnih površin pomembni dejavnik oblikovanja krajine $\mathrm{v}$ alpskem okolju. Zadružna organizacija se je v 19. stoletju razvila na podlagi državne podpore, kmetijske propagande, vpeljave švicarskega modela sirarstva, pa tudi zaradi specifičnega gorskega okolja, ki je zahtevalo skupno delo in skrb za planino, pašne površine, gozdove in poti (glej Valenčič, 1990, 31-32). »Veliko brigo je bilo treba posvečati dohodom do planin, živinskim ter pastirskim stezam, oskrbi z vodo, napajališčem itd.« (Melik, 1950, 134). 
Že Hitz je kritiziral razdrobljenost parcel in pomanjkanje pašnih površin, opozarjal pa je tudi na zaraščanje planin in pašnikov, ki se pojavi ob omejeni paši in opuščanju transhumance: »Živinoreja in dobro planinsko gospodarstvo sta tedaj najimenitnejša studenca za blagostan tukajšnjega kraja; zato potrebujeta neprenehoma posebno skrb « (Hitz, 1878, 327). Nadaljuje, da je zaradi razvoja živinoreje potrebno »umno« obdelovati pašnike in senožete. Kritizira pa "prečudne razmere pašnikov na Bohinjskih planinah«; poti so za živino naporne in dolge, planine pa zaraščene, zato živina dobi slabo hrano:

Namesti da bi pa tu dobila dobre in obilne paše, mora reva zadovoljna biti $s$ slabo in pičlo krmo, katero je prekoračivši dolge in skalnate poti, dobila na oddaljenih in pustih pašnikih; s tako pašo se komaj preživi, ne pa, da bi se mogla dostojno rediti in več mleka dajati.

Krivdo je zvalil na večinsko lastnico gozdov in pašnikov, Kranjsko obrtnijsko (industrijsko) družbo, ki je zaradi lesarstva zavirala razvoj planšarstva, paše na planinah in $\mathrm{v}$ gozdovih. Zaradi paše na prepovedanih pašnikih in $\mathrm{v}$ gozdovih je prihajalo do sporov, pritožb in borb za ohranitev pašnih pravic. Za ohranjanje planin in $s$ tem večstopenjskega planšarstva je ključno urejanje in vzdrževanje poti ter redna prisotnost živine na planinah, kar preprečuje njihovo zaraščanje. Zdaj so za to odgovorne agrarne skupnosti - če na planinah ne pasejo, jih morajo drugače čistiti, da preprečijo zaraščanje. Vojvoda navaja, da so pomembne spremembe nastopile v času socialistične Jugoslavije, ko so bile ukinjene lokalne srenje, s planinami pa so namesto njih upravljale kmetijske zadruge:

Zadruga je ostala zainteresirana za perspektivne planine in je opuščala slabe in neperspektivne pašnike. Prišlo je do selekcioniranega zboljševanja, čiščenja, intenziviranja pašnih površin na planinah in gmajnah, urejanja vodovodov, sirarn in hlevov, kar je vodilo v ohranjanje dobrih in opuščanje nerentabilnih planin (Vojvoda, 1995, 19).

Nadalje Vojvoda navaja, da je za oživljanje planinske paše pomembna predvsem prometna dostopnost. Na nekatere planine so namreč gradili ali razširili in utrdili vozne poti, ki so tako postale dostopne $\mathrm{z}$ avtomobili ali vsaj s traktorji. Na takih planinah in predvsem bivših senožetih se je poleg planšarstva ali ob njem pojavilo tudi vikendaštvo, saj so mnogi kmetje svoje pastirske stanove prodali ali spremenili v počitniške hiške zase in predvsem za oddajo. Anka Novak navaja primer kmeta iz Studorja, ki je med pozdravnimi govori na Kravjem balu podpiral povezovanje planšarstva s turizmom.

Sam je to idejo udejanjal tako, da je svojo stajo v Ukancu med prvimi predelal $\mathrm{v}$ počitniško hišico in jo oddajal letoviščarjem. Poleg očetove staje si je sin postavil stanovanjsko hišo ..., poleg nje pa še posebno zgradbo $\mathrm{z}$ apartmaji (Novak, 1989, 146). 
Prav Ukanc, ki leži neposredno ob zahodni obali Bohinjskega jezera, je med prvimi pašniki postal trajno turistično oziroma vikendaško naselje (prim. Bajuk, 2005, 89, 90). Tudi sogovornica s sirarske kmetije v Studorju je povedala, da je bil Ukanc nekdaj zelo pomembna senožetna planina za Studorsko-fužinarsko agrarno skupnost, sedaj pa je le vikendaško naselje. Ukanc in Goreljek sta leta »1984 imeli 148 počitniških hišic in 99 počitniških stanovanj v planšarskih objektih« (Vojvoda, 1995, 22). Zaradi izgradnje turistične infrastrukture in spremembe namembnosti $\mathrm{v}$ šestdesetih in sedemdesetih letih 20. stoletja je bil Ukanc izključen iz pašnih poti, po drugi strani pa je prav turistični razvoj Bohinja, ki je tako specifično zaznamoval spremembe $\mathrm{v}$ Ukancu, odprl prostor tudi za nove sirarske poti (npr. turistično sirarska pot).

Do neke mere se je podobno zgodilo tudi na višjih planinah (glej Ledinek Lozej, 2013, 56). Sogovornik, ki sicer pase na planini v Lazu, je povedal, da sta zadnja leta $» v$ planini le še dva majerja « (pastirja) ${ }^{2}$, medtem ko drugi stanovi ne propadajo, ampak se v njih počitnikuje: »Oddajati stanov se sicer ne sme, ampak lastniki to vseeno počnejo. «Čez planine nad Bohinjem vodijo tudi priljubljene planinske poti, zato pastirji lahko že na planinah prodajo svoje proizvode, zlasti kislo mleko, sir in skuto. Sodobno »oživljanje« planšarstva in "planšarske dediščine« se pogosto povezuje prav z dostopom do planin in $s$ turistično ter planinsko dejavnostjo, delno pa celo $\mathrm{z}$ razvojem vikendaštva na planinah (Novak, 1989). Lokalna turistična organizacija in turistična društva v Bohinju uporabljajo podobe planšarstva, gorske krajine, lokalnih proizvodov (tudi sira), prirejajo pa tudi različne dogodke, ki so namenjeni turistični prezentaciji »avtentične planšarske dediščine«. To so zlasti sejmi, na primer prej omenjeni Kravji bal, Kmečka ohcet in podobne prireditve, ki prezentirajo avtentičnost in tradicionalnost, na njih pa se prepletajo poti domačinov, sirarjev in turistov (prim. Bajuk, 2005, 83; Habinc, 2013). Planšarstvo pa je tudi del izkušnje planincev oziroma pohodnikov, saj mnoge priljubljene planinske poti vodijo čez pašne planine, kjer se planinci srečujejo s pastirji, živino, in pastirskim življenjem.

Pašne poti na planino so tudi planinske poti in so pod okriljem planinskih društev. Nadelali in vzdrževali so jih pastirji ali lovci, $\mathrm{z}$ razvojem planinske in turistične dejavnosti pa so se spremenile $\mathrm{v}$ gorske oziroma planinske peš poti. Tatiana Bajuk navaja, da sta prav planinstvo in alpinizem v poznem 19. stoletju predstavljali prva oblika turizma v Bohinju: »... [P] ovezava med turizmom in planinstvom [je] postala tako močna, da je beseda turist pomenila plezalca ali planinca« $(2005,76)$. Precej domačinov se je začelo ukvarjati $z$ vodenjem po gorah, ob tem so nadelali, utrdili in vzdrževali tudi poti. »Gorski vodniki so tudi odkrivali in gradili nove planinske poti ter sodelovali pri gradnji planinskih koč« (Bajuk, 2005, 76).

2 Pogosto se uporablja izraz v planini namesto na planini. Planina predstavlja več kot zgolj površino, gre za kompleksen kraj dela, bivanja, gibanja, življenja in zgodovine družbenih in medsebojnih razmerij. 
Sedanje pašne poti na planino so sicer pod okriljem planinskih društev in Planinske zveze Slovenije, a jih na različne načine uporabljajo in urejajo tudi druge institucije (na primer Triglavski narodni park, lovske družine, turistične organizacije) in akterji - planinci, kolesarji, gozdarji, lovci, vikendaši, pozimi tudi turni smučarji in seveda pastirji. Med gnanjem živine na planino je sogovornica povedala, kako se planinci včasih ustrašijo živine na poteh in ob tem dodala: »Imamo pa mi gotovo več pravic, ker pasemo gor. Je bila najprej naša pot." Kljub temu, da so posegi v okolje, sploh na območju Triglavskega narodnega parka, načeloma prepovedani, poti pa vzdržujejo markacijski odseki planinskih društev, jih pastirji pogosto popravljajo preden se odpravijo na basengo, gnanje živine na planino. ${ }^{3} \mathrm{Ob}$ tem se pojavlja tudi vprašanje nadelave novih ali širjenja obstoječih poti za traktorski dostop do planin. Ohranjanje planšarstva se pogosto povezuje prav z motoriziranim dostopom (prim. Ledinek Lozej, 2013, 56). Sogovornik, sirar na Planini v Lazu, je dejal, da je že lepo ohranjati planino mirno in dostopno le peš, a po drugi strani za sirarstvo potrebuje različne pripomočke, kot so agregat za molžo, gorivo ipd., ki jih je težko dostavljati kot nekoč, na konjih. Ob tem je omenil, da je leta 2005 eden od kmetov na lastno pest začel s traktorjem širiti pot na planino, kar so ustavili zaradi posredovanja Triglavskega narodnega parka. Dodal pa je, da je TNP prisluhnil potrebam planšarjev na planinah brez voznega dostopa in na planino oziroma $\mathrm{z}$ nje nekajkrat letno organizira prevoz materiala in izdelkov z vojaškimi helikopterji z Rudnega polja na Pokljuki.

Planine in gorske poti oblikujejo kulturno krajino, podvrženo politikam in praksam ekonomske, rekreacijske, avanturne, turistične in druge rabe gorskega okolja, kjer se spremembe odražajo v izsekavanju ali zaraščanju, pašni živinoreji, planinskih dejavnostih, uporabi planinskih poti, oznakah in različnih tematskih zemljevidih.

\section{Pletež poti, stez, cest in krajev $v$ družinski sirarski ekonomiji}

Vaške in planinske poti, ceste, steze, poti na pašnike in planine ter po planini, poti na tržnice in sejme itd. so linije, po katerih se gibljejo pastirji, sirarji in njihovi družinski člani. Na teh poteh in v krajih, ki jih poti povezujejo (kmetije, vasi, pašniki, planine, sejmi, tržnice itd.), se odvija življenje sirarske družine in njena ekonomska dejavnost. Gibanje po linijah, srečevanje, postajanje in delovanje ustvarja kraje, pomembne za sirarstvo - pašnike, planine, tržnice itd. -, oziroma jim daje njihov specifični značaj, ki je vtisnjen $\mathrm{v}$ kulturno krajino. To so linije in kraji, po katerih se odvijata življenje in

3 Planinske poti vzdržujejo in označujejo lokalna planinska društva in njihovi markacijski odseki.

Zakonsko sicer področje ureja Zakon o planinskih poteh. 
sirarska dejavnost. Linije in kraji gibanja in bivanja tvorijo pletež (ang. meshwork, glej Ingold, 2007, 80-81), po katerem se odvijajo življenja v kmečki, pastirski in sirarski družini.

Koncept pleteža je v antropologijo uvedel Tim Ingold, ki si ga je izposodil pri filozofu Henriju Lefebvru. Lefebvre je s pletežem označil:

retikularni vzorec, ki ga puščajo domače in divje živali ter ljudje (v hišah, vaseh, majhnih mestih in njihovih okolicah), katerih gibanje tke okolje, ki je bolj »arhiteksturno« kot »arhitekturno (Lefebvre, 1991, 117-118, citirano v Ingold, 2007, 80).

Ingold je pletež uporabil v kritiki sedentarističnega, teritorialnega razumevanja kraja. Trdi namreč, da človeška izkušnja kraja, posledično pa tudi poznavanje okolja in učenje izhajajo iz gibanja (po linijah) in ne iz evklidskega zemljevidenja krajev kot teritorialno zamejenih površinskih enot (Ingold, 2007; 2009). Ingold omenja dva načina gibanja, popotovanje (ang. wayfaring) in transport $(2007,75){ }^{4}$ Popotovanje (wayfaring) je najosnovnejši način bivanja in življenja v svetu. Poti gibanja pa spletajo pletež ali »svet« bivanja«, v katerem se odvija življenje: »Prepletenost linij in ne stikanje točk vzpostavlja pletež«, v katerem se odvija življenje oziroma bivanje v okolju (Ingold, 2007, 81; 2011, 10). Med gibanjem se odvija tudi učenje, spreminjanje okolja in oblikovanje krajev, ki so prepleti linij gibanja, srečevanja in delovanja. Za razliko od popotovanja (wayfaring) je transport način gibanja, ki je usmerjen v destinacije. Transport ne poteka po linijah, ampak gre za gibanje od točke do točke, pri katerem pot ni izkustveno pomembna. Linije transporta so »linije, ki povezujejo sledeče si destinacije ... in niso sledi gibanja, ampak povezave med točkami« (Ingold, 2007, 79).

V nadaljevanju torej obravnavam pletež poti in krajev, kjer se odvijata pastirska in sirarska dejavnost (na primer planinske poti in planine). Ta pletež sestavljajo dinamične linije gibanja, ki zajemajo vsakdanje življenje in delo vseh članov družine, osredotočim pa se predvsem na hojo na dnevno pašo v okolici vasi, basengo oziroma odgon živine na planine, gibanje po gorskem svetu, zlasti po planini, transport različnih stvari na planino in z nje, poti na tržnice in sejme, kjer prebivalci prodajajo svoje izdelke, in vključenost kmetije v turistično-sirarske poti.

Kot primer obravnavam turistično kmetijo in sirarno Gartner, $\mathrm{z}$ domačim imenom pr' Odolnek v Studorju v Zgornji bohinjski dolini. Ta kmetija leži v zahodnem delu spomeniško zaščitene vasi Studor, v dolu, torej na spodnjem delu gručasto poseljene vasi. Vas leži v Zgornji bohinjski dolini in v Triglavskem narodnem

4 Beseda popotovanje sicer ni idealen prevod, saj je v slovenskem jeziku bližje potovanju (travel) kot Ingoldovemu terminu wayfaring, ki pomeni hojo (po poti). Ker nisem našel boljšega prevoda, povsod, kjer se nanašam na ta koncept, dodajam angleški termin. 
parku, pod mogočno strmo steno gore Studor. Vzhodno sta Srednja vas in Bohinjska Češnjica, zahodno pa Stara Fužina. Družinska sirarska kmetija je zanimiva tudi zaradi pluralnih dejavnosti, ki se navezujejo na temeljno - kmetijsko - dejavnost. Poleg same kmetijske in sirarske dejavnosti se namreč ukvarjajo še s kmečkim turizmom in prodajo lastnih mlečnih, pekovskih in nekaterih mesnih izdelkov. Glavna dejavnost je sirarstvo, ki poteka tako v dolini kot tudi na Planini v Lazu, na kateri je nosilec kmetijske dejavnosti, sirar Gregor Gartner, med zadnjimi dejavnimi planšarji v agrarni skupnosti. Na kmetiji pridelujejo in prodajajo mlečne izdelke, predvsem sir po metodi ementalca, sir mohant, surovo maslo in skuto. Vsa družina je močno vpeta $\mathrm{v}$ kmetovanje in sirarstvo, a uradno je le Gregor nosilec celotne dejavnosti, medtem ko je žena Anica zaposlena izven kmetije.

Gregor je izučen mlekar in sirar, izšolal se je v mlekarski šoli v Kranju in je kot sirar delal v Bohinjski sirarni. Za lastno sirarsko pot sta se z ženo odločila leta 2000. Gregorjev oče je bil tudi majer (pastir), nikoli pa se ni ukvarjal s sirarstvom kot njegov sin. Kmetija pr' Odolnek je bila že vsaj od prve polovice 19. stoletja vključena v srenjo oziroma agrarno skupnost Studor-Stara Fužina, zato imajo pašno pravico na Planini $\mathrm{v}$ Lazu in nekaterih drugih planinah agrarne skupnosti, a poleti pasejo le v Lazu. Ko so na kmetiji začeli s sirarstvom, so povečali hlev ter poleg njega postavili sirarno in prodajalno mlečnih izdelkov. Prostor v hlevu jim dopušča vzrejo lastnih 12 ali $13 \mathrm{krav}$, ki jih poleti pasejo tudi na planini v Lazu. Občasno za potrebe sirjenja v dolini tudi odkupijo mleko, čeprav »zaradi foušije raje ne več od bližnjih kmetov, ampak od kmetov iz okolice Bleda«.

Reja goveda je povezana $\mathrm{z}$ rutinskim delom v hlevu in sirarni. Pozimi živino krmijo $\mathrm{v}$ hlevu, od pomladi do pozne jeseni pa na pašnikih v bližini vasi. $\mathrm{V}$ tem obdobju po jutranji molži odženejo živino na pašnike, med katerimi kolobarijo. Ta hoja v okolici vasi je sicer rutinska, a razkriva odlično poznavanje lastništva in razdelitve pašnih površin. Pod kmetijo namreč spada več manjših pašnih in drugih obdelovalnih zemljišč, ki so razdrobljena v vasi in njeni bližini. Razdelitev zemljišč je povezana $\mathrm{z}$ zgodovino delitev in združevanj kmetij skozi poroke, prodaje, dedovanja in prevzeme ter $\mathrm{z}$ nacionalizacijo večjih kmetij v času socialistične Jugoslavije. Navidezno povsem vsakdanja, rutinska hoja je torej povezana s poglobljenim poznavanjem prostora, parcelnih delitev, njihovih zgodovin, meja in lastniških odnosov.

Posebej pomembna sta odhod z živino na planino in vrnitev v dolino. Gartnerjevi čez poletje molzne krave ženejo le na Planino v Lazu, ki je z nadmorsko višino 1560 metrov med višjimi in bolj oddaljenimi planinami. Odgon živine ali basanje je poseben dogodek za vso družino, saj zahteva veliko priprav na dvomesečno selitev, bivanje in delo v gorskem okolju. Tone Cevc je zelo romantično opisal ta dogodek: 
[T]rdnemu bohinjskemu kmetu se zjasni obraz, ko pomisli na svoje planine na pastirska selišča s pašniki in gorami, ki jih obdajajo. Že sama misel na selitev v planine jih prevzame (1992, 44-45).

Anka Novak pa je povsem drugače in prav nič romantično opisala, kako se pastirji, ki so že v mladosti pasli, spominjajo naporov in težkega dela na planinah:

Povečini se $\mathrm{s}$ trpkostjo spominjajo otroštva, zaznamovanega $\mathrm{z}$ napori, domotožjem v trdem gorskem okolju. Nekateri so od otroštva vztrajali pri majerskem poklicu, ostali so samski in se starali ob delu v planinah $(1989,128)$.

$\mathrm{V}$ vsakem primeru je odhod na planino pomemben mejnik tako $\mathrm{v}$ letnem življenjskem ciklu pastirja in sirarja kot tudi v ekonomskem smislu. $\mathrm{Na}$ izrecno vprašanje, kateri so glavni razlogi za pašo na planini, je sogovornica odgovorila, da je zelo pomembno, da kmetiji ni treba skrbeti za hrano za živino za vsaj dva meseca. Poleg tega sir, ki je narejen v planini, označijo kot planšarski sir in je še posebej cenjen tako med domačini kot turisti. Tudi sam sirar je povedal, da je sir drugačen zaradi okolja, v katerem ga proizvaja, predvsem pa zaradi gorske paše: „Gor krave jedo veliko bolj zdravo hrano kot $v$ dolini. Tam je paša bolj sveža, jedo pa veliko trav, ki so zelo zdrave. Če so bolne, kar same vedo, katere rožice morajo jesti, da se pozdravijo. "Sirar je tudi večkrat omenil, da dajo v planini manj mleka kot v dolini, vendar je »bolj polno«.

Sodelovanje pri hoji in basanju oziroma odgonu živine iz Studorja na Planino v Lazu na začetku poletja 2013 je bilo po eni strani zanimivo etnografsko delo med hojo (prim. Ingold in Vergunst, 2008), predvsem pa dober uvid v pomen zelo raznovrstnih praks gibanja, ki so neločljiv del življenja, dela in ekonomije na sirarski kmetiji. O poletnem odhodu živine na planino smo že prej večkrat govorili kot o pomembnem mejniku v življenju sirarja in njegove družine, zlasti pa v sirarski dejavnosti. Omenjena pot je bila celo del dodatne (a nekomercialne) turistične ponudbe v okviru kmečkega turizma - poleg mene so se je udeležili še štirje »turisti«, ki so jim pomagali že prejšnje leto.

Večer pred odhodom na planino smo se nastanili na kmetiji in med pitjem čaja opazovali zadnje mrzlične priprave na zgodnji jutranji odhod. Priprave so zahtevale vrsto opravil, od preverjanja stanja živine, organizacije prevoza za del črede in stvari ter priprave hrane in pijače za sirarja, ki bo ostal na planini, in celo za spremljajoče »turiste«. Vmes, ko se je Anica ukvarjala s »turisti«, je Gregor vsake toliko prišel v kuhinjo in preverjal, ali je vse pripravljeno, in nam večkrat naročil, naj vstanemo zgodaj, saj bomo ob petih zjutraj že odšli. Zjutraj smo res vstali zgodaj, a po zajtrku in kavi smo opazili, da kljub temu že malo zamujamo. Hitro smo pospravili stvari v nahrbtnike, jih dali v avtomobil, vzeli vsak svojo lepo izrezljano leseno palico, ki je osnovni pripomoček pri gnanju živine, dobili kratka navodila, naj kravam preprečimo, 
da bi zatavale s poti, in odšli. Vodila nas je sirarjeva hči Lucija, ki je imela na začetku več dela s petimi »turisti« kot s kravami. Krave so bile namreč prvega dela poti že vajene, saj je vodila po isti poti kot na dnevne pašnike v bližini vasi. Od kmetije smo se po cesti spustili do spodnjega dela vasi v smeri Stare Fužine, ki je oddaljena približno pol ure hoje. Pot vodi ob strmem pobočju na eni in pašnikih na drugi strani. Krave so sprva prepoznale pot na pašnike in želele zaviti tja, kmalu pa so ugotovile, da je tokrat pot drugačna. Lucija je povedala, da točno prepoznajo pot, ko gredo na planino: »V̌́asih kar pobezljajo od navdušenja, ko ugotovijo, da gremo na planino."

Pot je vodila do Stare Fužine in preko Hudičevega mostu na cesto proti Planini Blato, ki je sicer tudi priljubljeno izhodišče za planince. Cesto smo povsem zasedli, tako kot kasneje planinsko pot od Planine Blato do Planine v Lazu. ${ }^{5}$ Nekaj krav so do Planine Blato pripeljali kar v prikolicah in so se nam tam pridružile, eno kravo, ki je bila breja, pa je Gregor s traktorjem peljal vse do Planine pri Jezeru, ki je najbližje Lazu, in jo sam počasi prignal do svoje planine. Na vprašanje, zakaj nismo vsi šli čez Planino pri Jezeru, je pojasnil, da bi se tam krave pognale proti vodi in na pašnike in bi jih težko spet zbrali. Celotna pot je zaradi vročine trajala kar sedem ur in Gregor je bil vidno pomirjen, ko smo v planino prignali vse krave. Povedal je, da se na poti lahko dogodi marsikaj in začel praviti zgodbe o pripetljajih med basanjem v prejšnjih letih. Nekoč jim ene krave ni uspelo spraviti čez najbolj strm del poti: »Tam, kjer so tri stopnice, ni šla več čez. Tri dni sem jo hodil gledat in hranit, potem sem jo pa s konjem komaj čez povlekel.«Hoja z živino poteka v drugačnem ritmu kot brez nje, zato sta drugačna tudi dojemanje okolja in interakcija $\mathrm{z}$ njim. Na pot in njene posamezne dele se vežejo spomini, ki vključujejo dogodke ob hoji, vreme, razmere in okolje (glej Ingold, 2010). Med hojo je Anica večkrat omenila primerjavo s prejšnjim letom, ko je »šla sodra«. Špela Ledinek Lozej navaja, da »življenje v planini zahteva tudi dobro poznavanje terena, rastlin, vremena in zdravljenja živine« $(2013,53)$. K temu bi dodal, da zahteva tudi dobro poznavanje krajine, predvsem poti na planino, v njeni okolici in med planinami, ter različne oblike gibanja $\mathrm{v}$ gorskem svetu ter med dolinskim in gorskim okoljem.

Popotnik (ang. wayfarer) je bitje, ki med sledenjem poti življenja izpogaja in improvizira prehod, ko se giblje. ... Ob poti se odvijajo dogodki, opazovanje, življenje (Ingold, 2010, 126).

Čeprav je Gregor v prvi vrsti pastir in sirar, zelo dobro pozna poti v okolici planine in različne vremenske razmere skozi vse leto. Pogovori so nanesli na možne vzpone po okoliških gorah, turnosmučarske poti in cilje, plazove pozimi, divje živali, steze $\mathrm{v}$

5 Z gozdno cesto Stara Fužina - Voje - Vogar - Planina Blato upravlja agrarna skupnost. Večji del je asfaltiran, cesta pa je plačljiva (med turistično sezono). Je zelo priljubljena med planinci in jadralnimi padalci ter drugimi obiskovalci bohinjskih planin in gora. 
okolici, vodne izvire in podobno. Mimoidoči planinci se ustavijo pri njegovem stanu, poleg mlečnih izdelkov jim ponudi še znanje o planini in okolici, pokaže bivališča svizcev ali steze druge divjadi, svetuje o okoliških hribih, stanju poti, razdaljah, zanimivostih, vremenu itd. Obenem pa se njegova percepcija okolja razlikuje od pohodnikove, saj so tudi način gibanja in motivi zanj drugačni. ${ }^{6}$

Gibanje, torej predvsem hoja, je način učenja, ki se odvija skozi prakso, torej s hojo na planine oziroma $\mathrm{z}$ vsakdanjim gibanjem skozi alpsko gorsko okolje. Hoja po poti je gibanje skozi kraje, ki jih pohodnik pozna in katerih zgodovine so povezane $\mathrm{z}$ gibanjem skozi njih (Ingold, 2000, 227). Gibanje v gorskem svetu vključuje tudi druge prakse, kot so urejanje poti, gradnja in popravila stavb, ograd in vodovoda, poznavanje gorskih napajališč ter izkoriščanje pašnih površin na planinah in v okolici. Gibanje po planini je premišljeno in vpeto $\mathrm{v}$ sirarstvo: pri paši se kolobari po različnih delih planine, veliko je opravil, ki zahtevajo hojo med sirarno in stanom, pa tudi dlje v okolici (na primer nabiranje suhljadi, odgon in zbiranje živine itd.). Pomemben je tudi transport različnega materiala (gradbenega materiala, orodij, hranil za živino in pastirja) na planino ter sira in drugih izdelkov v dolino. Ker Planina v Lazu ni povezana s cesto, precej transporta poteka na tradicionalen način, s konjem med Planino v Lazu in Planino pri Jezeru, od tam v dolino pa s traktorjem. Zadnja leta Triglavski narodni park vsaj enkrat med pašno sezono organizira helikopterski prevoz goriva za agregat, gradbenega materiala in drugih stvari na planino. Na ta način želijo ohranjati planšarstvo na planini, ki nima cestne povezave $\mathrm{z}$ dolino.

Poznavanje okolja zajema lastništva in delitve kmečkih zemljišč ter povezanih družbenih razmerij, poti, planine $\mathrm{z}$ okolico, pašniki in gorskimi vrhovi, izvire in napajališča ob poteh in na planinah, meje med planinami, rastlinstvo in živalstvo, vremenske značilnosti v različnih letnih časih, načine gibanja itd. Gibanje, bivanje in delo na planini pa ima tudi posledice v kulturni krajini: poti se ohranjajo prav zaradi hoje po njih, paša ohranja planine in jih varuje pred zaraščanjem, čez »žive" planine pa pogosto vodijo priljubljene planinske poti ter tako postanejo del planinskih in turističnih itinerarijev. Pohodniki se na planini ustavijo, se naužijejo gorskega okolja in zaužijejo v planini pridelano kislo mleko, skuto in sir ter ga nekaj odnesejo v dolino. $S$ tem, ko se ustavijo na planini, se srečajo s pastirji in drugimi planinci, planina tudi zanje postane pomemben kraj na poti. Planina v Lazu je na primer priljubljena ne le poleti, temveč tudi pozimi, ko turni smučarji potegnejo nove začasne poti v sneg in $\mathrm{s}$ svojimi zavoji deviške linije po pobočjih.

Planine so kraji na poteh pastirjev, pohodnikov, alpinistov, turnih smučarjev itd. Čeprav sem največji del pozornosti namenil basanju in planinskim potem, je

6 O percepciji gorskega okolja med pohodniki glej Lorimer in Lund, 2008; razlike v prostorski percepciji med domačini in turisti pa so opisali Kianicka in drugi, 2006; prim. Ingold, 2000. 
treba vsaj omeniti tudi druge vrste poti, ki so del sirarske dejavnosti. Turistična in ekonomska infrastruktura $v$ Bohinju namreč obsega tudi druge poti, po katerih se odvija sirarstvo. Med njimi je turistično-sirarska pot, ki sta jo vzpostavila sirarsko in turistično društvo $\mathrm{v}$ Bohinju. Kmetija je našla pot na tematske zemljevide in $\mathrm{v}$ turistične itinerarije: na primer s skupinskimi degustacijami ali posamičnimi popotniki, ki se ustavijo zaradi nakupa mlečnih izdelkov in zgodbe, ki jo ti obenem ponujajo. Zelo pomembne so tudi prodajne poti. V prodajni mreži sodeluje vsa družina, predvsem pa žena in oba otroka. Te poti so prav tako redne: potekajo vsak teden na tržnico v Bohinjski Bistrici, poleg tega pa vsaj enkrat na mesec še na nekatere druge tržnice v okolici: na Bledu, Jesenicah itd. Za nekatere sirarje so pomembne tudi prodajne mreže neposredno gostinskim podjetjem, sicer pa mali domači sirarji svojih izdelkov ne prodajajo prek trgovskih verig, ampak zgolj sami. $\mathrm{Na}$ tržnicah prodajajo sir ementalec, planšarski in dimljeni sir, sir mohant, sirarsko skuto, surovo maslo, nekateri pa še mesnine (zaseko, klobase) in pekovske izdelke (potice, piškote). Tržnice so prav tako kraji, kjer se odvija kmečka sirarska dejavnost in se srečujejo poti: tam se srečajo s kupci, ki so prav tako na svojih poteh. Poleg tržnic so za prodajo sira in mlečnih izdelkov zelo pomembni še sejmi, zlasti Kravji bal v septembru, ki obeležuje prihod živine s planin in je tudi turistično folklorna prireditev (opis glej pri Habinc, 2013).

\section{Zaključek}

Sirarstvo v Bohinju je skozi vso zgodovino temeljilo na različnih načelih družbene organizacije in medsebojne vzajemnosti v kmetovanju in urejanju gorskega okolja. $\mathrm{V}$ predfevdalnem in fevdalnem obdobju je bila glavna organizacijska oblika srenja kot lokalna družbena organizacija skupnega dela in pašnih pravic $\mathrm{v}$ planinah. $\mathrm{Z}$ nastankom sirarskih društev $\mathrm{v}$ poznem 19. stoletju se je začela prava zadružna organizacija kmetijsko-pašne in sirarske dejavnosti. Zadružni model je nadgradil srenjsko organizacijo - delno s skupno pašo, predvsem pa s skupnim sirarstvom na planinah in v dolini. Člani zadrug oziroma agrarnih skupnosti so participirali pri delu, urejanju planin, poti, gradnji sirarn, paši in trgovanju. Ekonomska oblika vzajemnosti v agrarni skupnosti je segala tudi na področje družbenega življenja in praznovanja v lokalnih okoljih. V času Jugoslavije so vlogo lokalnih zadrug prevzele kmetijske družbe, po osamosvojitvi Slovenije pa zopet agrarne skupnosti. Vmes se je sicer močneje uveljavila hlevna živinoreja, a planšarstvo ni zamrlo - v zadnjih letih so na nekaterih planinah opazni celo poskusi »oživljanja« planin in planšarske dediščine. Tako so v zadnjih letih zopet začeli s pašo na Voglu, ki je sicer pomemben predvsem za turizem in planinstvo. 
Po letu 2000 se je poleg Bohinjske sirarne v Srednji vasi s sirarstvom začelo ukvarjati nekaj manjših družinskih sirarskih kmetij, ki so se naslonile na tradicionalno znanje. Delno je bil razmah družinskega sirarstva vezan tudi na širše kapitalistične procese in reorganizacije $\mathrm{v}$ devetdesetih letih 20. stoletja. Ena od sirark, ki je bila zaposlena $\mathrm{v}$ Bohinjski sirarni, preden je sama začela $s$ to dejavnostjo na domači kmetiji, je povedala: „Najprej je prišlo do privatizacije, potem je šlo vse $k$ vragu, ... zdaj sirarna po novem zagonu spet deluje zelo dobro. "Delno pa je bil pojav družinskega sirarstva vezan tudi na oblikovanje različnih prekrivajočih se turističnih itinerarijev in procesov vzpostavljanja prepoznavne, »avtentične« lokalnosti (prim. Pratt, 2007; Grasseni, 2011). Primer tega je bila nacionalna, kasneje pa celo evropska zaščita označbe geografskega porekla sira mohant (2004 in 2013).

Sirarske kmetije so tudi akterji v produkciji lokalnosti, saj se sklicujejo na kulturno dediščino, tradicionalne oblike paše in pridelave mlečnih izdelkov ter alpsko krajino. Planšarstvo je vedno imelo pomemben vpliv na oblikovanje kulturne krajine ter rabe in organizacije prostora. $\mathrm{V}$ oblikovanju in ohranjanju poti, stez in planin se je prepletlo s planinstvom, planinskimi društvi, gorskim turizmom in počitnikovanjem, od šestdesetih let 20. stoletja dalje tudi z razvojem vikendaštva na bivših senožetih ali na visokih planinah. Pri vseh družinskih kmetijah je sirarstvo zasebna, družinska dejavnost, ki jo kombinirajo s službami izven kmetije in $\mathrm{z}$ drugimi dopolnilnimi dejavnostmi, kot so prodaja pekovskih izdelkov, turistične ponudbe, degustacije itd. Obenem pa so sirarske kmetije vključene še v agrarne skupnosti (na primer zaradi paše na skupnih pašnikih in planinah, uporabe sirarne) in $\mathrm{v}$ bohinjsko turistično infrastrukturo (sirarska pot, sejmi, prireditve in festivali, prodaja na tržnicah itd.). Družinska kmetija je tako vključena $\mathrm{v}$ različne širše ekonomske strategije (prek agrarne skupnosti in turistične infrastrukture), kar ne pomeni organske vključenosti v skupnosti, ampak izpogajane odnose vzajemnosti. Sodobni razvoj sirarstva v Bohinju se opira na tradicionalne oblike družbenih in ekonomskih vzajemnosti, ki so temelj za oblikovanje in ohranjanje pašništva na planinah in gorskega okolja.

V tem prispevku sem se posebej osredotočil na pletež poti, stez, cest in krajev, kjer se odvija sirarska dejavnost - od paše ter proizvodnje mleka in mlečnih izdelkov do njihove prodaje in turistične promocije. Koncept pleteža je v tem primeru uporaben, saj analizo osredotoči na ponavadi dokaj zanemarjen vidik povezave med gibanjem, kmetijstvom in oblikovanjem ter percepcijo okolja, kar je še posebej pomembno v transhumantni živinoreji. Sirarstvo ni statično, je neločljivo povezano s hojo ter drugimi oblikami gibanja in transporta: po znanih in uhojenih poteh na pašo, na planine in v njihovi okolici, prodajo na tržnicah in sejmih ter drugod po prodajnih mrežah. Gibanje, poti, transport, ceste, planine, tržnice in sejmi so neločljiv del družinske sirarske ekonomije, kjer so sicer določene starostne, spolne in formalne 
vloge, a niso strogo segregirane, saj je vsa družina močno vpeta v temeljno kmečko dejavnost. $\mathrm{Z}$ gibanjem je povezano tudi znanje o kmetijstvu, sirarstvu, tehnologiji in okolju. Predvsem je pomembno znanje, vezano na planšarstvo in krajino, ki jo soustvarja in skozi katero se odvijata gibanje in življenje.

\section{Literatura}

Bajuk Senčar, T., Kultura turizma: Antropološki pogled na razvoj Bohinja, Ljubljana 2005.

Belrupt, grof, Sirarstvo v Bohinji na Gorenjskem: Iz nemške knjižice pod naslovom »Oesterreichische Melkerei-Genossenschaften im Jahre 1874«, Novice, 28. april in 5. maj 1875.

Cevc, T., Bohinj in njegove planine: Srečanja s planšarsko kulturo, Radovljica 1992.

Grasseni, C., Re-inventing food: Alpine cheese in the age of global heritage, Anthropology of Food 8, 2011, http://aof.revues.org/6819 [23. 4. 2014].

Habinc, M., Tradicionalnost prireditev Kravji bal, Vasovanje in Kmečka ohcet $\mathrm{v}$ Bohinju s perspektive njihovih organizatorjev, Traditiones 42 (2), 2013, str. 85104.

Hitz, T., Napredek sirarstva v Bohinji na Gorenjskem, Novice, 23. avgust 1876, str. 269-270.

Hitz, T., Razmere pašnikov v Bohinju, Kmetijske in rokodelske novice, 19. oktober 1878, str. 327-328.

Ingold, T., The Perception of the Environment: Essays on Livelihood, Dwelling and Skill, London, New York 2000.

Ingold, T., Lines: A Brief History, London, New York 2007.

Ingold, T., Against Space: Place, Movement, Knowledge, v: Boundless Worlds: An Anthropological Approach to Movement (ur. Kirby, P. W.), New York, Oxford 2009, str. 29-43.

Ingold, T., Footprints through the Weather-World: Walking, Breathing, Knowing, Journal of the Royal Anthropological Institute 16, 2010, str. 121-139.

Ingold, T., Being Alive: Essays on Movement, Knowledge and Description, New York 2011.

Ingold, T., Vergunst J. L. (ur.), Ways of Walking: Ethnography and Practice on Foot, Hampshire, Burlington 2008.

Jeraj, A., Objekti in delovni pripomočki na pašnih planinah. Diplomsko delo, Univerza v Ljubljani, 2012. 
Kianicka, S. in drugi, Locals' and Tourists' Sense of Place: A Case Study of a Swiss Alpine Village, Mountain Research and Development 26 (1), 2006, str. 55-63.

Ledinek Lozej, Š., Pričevanja o nekdanji ureditvi in življenju v planini Krstenica, Traditiones 31 (1), 2002, str. 69-90.

Ledinek Lozej, Š., Paša in predelava mleka v planinah Triglavskega narodnega parka: kulturna dediščina in aktualna vprašanja, Traditiones 42 (2), 2013, str. 49-68.

Lorimer, H., Lund K., A Collectable Topography: Walking, Remembering and Recording Mountains, v: Ways of Walking: Ethnography and Practice on Foot (ur. Ingold, T., Vergunst, J. L.), Hampshire, Burlington 2008, str. 185-200.

Melik, A., Planine v Julijskih Alpah, Ljubljana 1950.

Novak, V., Slovenska ljudska kultura: Oris, Ljubljana 1960.

Novak, A., Življenje in delo planšarjev v bohinjskih gorah, Glasnik SED 29 (3-4), 1989, str. 121-152.

Novak, A., Življenje in delo planšarjev v Bohinju, v: Planšarske stavbe v vzhodnih Alpah: Stavbna tipologija in varovanje stavbne dediščine (ur. Cevc, T.), Ljubljana 1995, str. 25-39.

Pratt, J., Food Values: The Local and the Authentic, Critique of Anthropology 27 (3), 2007, str. 285-300.

Simonič, P., Pretekle in sodobne oblike skupnega v dolini Trenti, Ars \& Humanitas 8 (1), 2014, str. 15-37.

Solnit, R., Wanderlust: A History of Walking, London 2000.

Tilley, C. Y., A phenomenology of Landscape: Places, Paths, and Monuments, Oxford, Providence 1994.

Valenčič, V., Začetki organizacije našega mlekarstva, Kronika 38 (1/2), 1990, str. 30-43.

Vojvoda, M., Geografska oznaka planinskega gospodarstva v Bohinju, v: Planšarske stavbe v vzhodnih Alpah: Stavbna tipologija in varovanje stavbne dediščine (ur. Cevc, T.), Ljubljana 1995, str. 12-24. 
Jaka Repič

\section{Gibanje kot prostorske prakse in ekonomske strategije na primeru družinskega sirarstva $v$ Bohinju}

Ključne besede: Bohinj, gibanje, poti, krajina, sirarstvo, družinske kmetije

Članek obravnava družinske sirarske kmetije $\mathrm{v}$ Bohinju in analizira njihove ekonomske strategije $\mathrm{v}$ povezavi $\mathrm{z}$ družinsko in zadružno obliko sirarstva ter $\mathrm{v}$ povezavi z različnimi oblikami prostorskega gibanja oziroma mobilnosti. $\mathrm{V}$ zadnjem desetletju se je več družinskih kmetij (ponovno) začelo ukvarjati s sirarstvom, ki je močno povezano s tradicionalnimi oblikami zadružništva in pašnimi pravicami agrarnih skupnosti. Kmetije so se naslonile na tradicionalne oblike sirarstva in obenem oblikovale nove ekonomske strategije, ki zajemajo predvsem pluralnost njihovih dejavnosti - delo izven kmetije, turizem, prodaja izdelkov itd.

Članek na kratko predstavi razvoj sirarstva v Bohinju, spremembe v zasebni oziroma zadružni organizaciji dejavnosti, predvsem pa izpostavi gibanje in pletež poti, stez, cest in krajev, ki so temeljno povezani s sirarsko ekonomijo. Pri tem poveže različne prakse gibanja, med njimi dnevno pašo ob vaseh, pastirstvo, pašo na planinah ter prodajo sira in mlečnih izdelkov na tržnicah in sejmih. Skozi analizo gibanja članek poveže ekonomske strategije sirarskih kmetij, modelov zadružništva in zasebne produkcije ter konceptualizacije in organizacije prostora - zlasti poti, planin in drugega pašnega okolja. 


\author{
Jaka Repič
}

\title{
Movement as Spatial Practices and Economic Strategies in Cheese Production at Family Farms in Bohinj
}

Keywords: Bohinj, movement, paths, landscape, cheese production, family farming

The article explores dairy and cheese production at family farms in Bohinj, their economical and organisational strategies (variations between family and cooperative organisation of farming) and the connection of cheese production with different modes of spatial movement. In the past decade, several family farms have started producing cheese and milk products, which is an economic activity closely linked to traditional forms of cooperatives, and pasture rights of agricultural societies. These farms have revitalised traditional forms of cheese production and established new economic strategies, especially through the plurality of their activities - work outside of the farm, tourism, marketing of their products, etc.

The article first presents a development of cheese production in Bohinj, changes in family and cooperative farming and explores movement and the meshwork of paths, tracks, roads and places that are fundamental to cheese economy. Further, the article connects different movements, e.g. daily pastures close to the villages, transhumance in mountain pasturelands, selling products in markets, etc. Modes of movement (walk, cattle herding, driving to markets) are basic practices behind economic strategies of dairy and cheese farms, as well as organisations and use of space, in particular mountain paths and pasturelands. 